\title{
QUALITY OF LIFE IN THE LATE FOLLOW-UP OF ULCERATIVE COLITIS PATIENTS SUBMITTED TO RESTORATIVE PROCTOCOLECTOMY WITH SPHINCTER PRESERVATION OVER TEN YEARS AGO
}

\author{
Alberto Luiz Monteiro Meyer, Magaly Gêmeo Teixeira, Maristela Gomes de \\ Almeida, Desidério Roberto Kiss, Sergio Carlos Nahas, Ivan Cecconello
}

doi: $10.1590 / \mathrm{S} 1807-59322009000900008$

\begin{abstract}
Meyer ALM, Teixeira MG, Almeida MG, Kiss DR, Nahas SC, Cecconello I. Quality of life in the late follow-up of ulcerative colitis patients submitted to restorative proctocolectomy with sphincter preservation over ten years ago. Clinics. 2009;64(9):877-83.
\end{abstract}

OBJECTIVE: To evaluate, by means of the Inflammatory Bowel Disease Questionnaire (IBDQ), the quality of life of ulcerative colitis patients submitted to proctocolectomy with sphincter preservation using J-pouch reconstruction over ten years ago.

METHODS: The study consisted of 36 patients interviewed using the Inflammatory Bowel Disease Questionnaire. The score scale, resulting from the addition of each answer, ranged from 32 to 224, where the highest score indicates the best quality of life. The chi square test was used to verify the existence of meaningful differences between the results of the questionnaire and age, and gender proportion. For each section, as well as for all of them combined, the Kruskal-Wallis test was used to verify if there were differences in the Inflammatory Bowel Disease Questionnaire scores among the groups in relation to the proportions.

RESULTS: After applying the Inflammatory Bowel Disease Questionnaire, it was determined that quality of life was considered excellent for $9(25 \%)$, good for $11(30.6 \%)$, regular for $13(36.1 \%)$, and bad for $3(8.3 \%)$ patients. In our study, we determined that $85 \%$ of the patients were pleased with and thankful for the surgery that they underwent.

CONCLUSION: We can conclude that the possibility of sphincter preservation should always be taken into account, since patients remain clinically stable and have a high quality of life even after long periods.

KEYWORDS: Quality of life; Patient satisfaction; Follow-up studies; Ulcerative Colitis/surgery; Restorative proctocolectomy/ methods.

\section{INTRODUCTION}

Ulcerative colitis has its onset preferentially in young people within the second to fourth decades of life, with a second onset peak when at 60 years of age and older. Its incidence is increasing in developing countries, whereas rates seem to remain stable in developed countries. ${ }^{1,2}$

In a study carried out at the Rectum and Colon Service of Hospital das Clinicas da Faculdade de Medicina da

Rectum and Colon Service, Department of Gastroenterology, Faculdade de Medicina da Universidade de São Paulo - São Paulo/SP, Brazil.

Email: almmeyer@yahoo.com

Tel: 55113069.7560

Received for publication on May 08, 2009

Accepted for publication on June 29, 2009
Universidade de São Paulo (HC-FMUSP), an incidence rate of 22 new cases per year was observed, afflicting, with greater frequency, Caucasian people with a higher socialcultural status. ${ }^{1}$

Even though the death rate is relatively low, its high morbidity interferes significantly with the quality of life of patients, often causing social and workplace anxiety.

Most of the people affected can have their disease clinically controlled; however, as ulcerative colitis progresses, it is estimated that 20 to $30 \%$ of the patients will eventually need surgical treatment, ${ }^{3}$ since clinical treatment is no longer effective.

Proctocolectomy with ileal pouch-anal anastomosis has revolutionized the surgical therapy of ulcerative colitis, making it the surgery of choice, especially for young adults, 
since it removes all of the disease and allows sphincter conservation. $^{4}$

J-pouch reconstruction, introduced in $1987^{5}$ and later by Kiss, ${ }^{6}$ is the most commonly used reconstruction due to the volume capacity obtained, simplicity in execution, ease of reaching the anal canal, and elimination of the possibility of spontaneous transanal evacuation. Furthermore, J-pouch reconstruction does not require catheterization like the S-pouch reconstruction does. ${ }^{4}$

The focus of interest is on studying the quality of life of patients who have undergone proctocolectomy with ileal pouch-anal anastomosis and assessing the systemic, emotional, and social parameters that may interfere with the day-to-day lives of these patients. ${ }^{7}$

International literature suggests that the establishment of functional parameters takes place a year after the surgery or the closing of the ileostomy, if one is used, ${ }^{8-12}$ allowing time for an adequate evaluation of the results after this period.

The World Health Organization defines quality of life as "the perception of the individual of his/her position in life in the cultural context and the value system in which he/she lives in relation to his/her objectives, expectations, standards, and concerns". ${ }^{13}$ In this definition, it is implied that the concept of quality of life is subjective, broad, and includes elements of both positive and negative impact.

In order to study quality of life after a surgery, the Inflammatory Bowel Disease Questionnaire (IBDQ) is used. It is a reliable measure, has good reproducibility, and reflects the important changes that occur in the health state of intestinal bowel disease patients. It can be used to thoroughly verify the impact, effectiveness, and efficiency of therapeutic measures. The IBDQ has recently been translated and validated into the Portuguese language. ${ }^{14}$

Using this questionnaire at HCFMUSP, we have studied the quality of life of patients who have undergone proctocolectomy with ileal pouch-anal anastomosis for ulcerative colitis after an average of five years postoperation. At that time, the questionnaire had not yet been validated. It was observed that $73 \%$ of the patients claimed that their quality of life was considered great or good after the surgery. ${ }^{15}$

It has been published in the literature that long-term patients, 10 years or more post-operation, develop a large number of fistulas that connect the ileal pouch to the perineum and vaginal skin, as well as a large number of pouchitis. ${ }^{16}$

We are not aware of national studies (PUBMED database) that evaluate the quality of life of patients who have undergone surgery ten years earlier. For this reason, we have decided to publish this study, employing the same methodology used in a Masters degree that was presented to, and approved by, the Gastroenterology Department at FMUSP, which was later published ${ }^{15}$ after the IBDQ was validated in Brazil.

The goal of the present study was to assess the quality of life of IBD patients who have undergone proctocolectomy with ileal pouch-anal anastomosis over ten years ago at the Rectum and Colon Services of the Medical School of the University of São Paulo by employing the IBDQ.

\section{METHODS AND MATERIALS}

The study was composed of ulcerative colitis patients who underwent proctocolectomy with ileal pouch-anal anastomosis over ten years ago. These patients have been see at the Rectum and Colon Surgery Ambulatory Services of the Second Surgical Clinic Division of Hospital das Clinicas da Faculdade de Medicine da Universidade de São Paulo since 1985.

All patients who have undergone surgery at Hospital das Clinicas da Faculdade de Medicine da Universidade de São Paulo within the years from 1985 to 1995 , who did not require an ileostomy because of post-operative complications or those whose temporary ileostomy had been closed were included in this study.

The patients gave their written consent after being informed by the author of the goals, methods used, and risks and benefits of this research.

Patients who underwent surgery using videolaparoscopy, missed the ambulatorial follow-up, were children, and failed to understand the questionnaire were excluded from this study.

The patients were interviewed during their regular visit for the post-operative observation or through requests made for an appointment via telephone contact.

The author has interviewed the patients using the IBDQ at the Hospital das Clinicas da Faculdade de Medicine da Universidade de São Paulo.

The IBDQ is comprised of 32 items that consider 4 areas (or dimensions): Intestinal symptoms (evacuation frequency, abdominal pain and/or cramps, degree of continence, and evacuation urgency), systemic symptoms (nausea, fatigue, insomnia, and weight loss), social aspects (working ability and social and leisure activities), and emotional aspects (behavior changes, irritability, anger, melancholy, and degree of satisfaction in relation to the surgery).

The questionnaire was multiple choice, consisting of a 7-point Likert scale, with 1 being the worst quality of life and 7 the best. The range of final scores, which results from adding the value of each answer, varied from 32 to 224 , with the higher scores being an indicator of a better quality of life.

The length of time needed to complete the questionnaire varied from 15 to 45 minutes. The patient, previously 
instructed on how to answer the questionnaire, chose from a chart with choices numbered from 1 to 7 the choice that best answered the question posed. The questions were repeated, so as to clarify the patient's understanding that the desired data were those from two weeks prior to the interview.

Clinical studies published in the literature that use the IBDQ ${ }^{17-20}$ simplified interpretation of the data in the questionnaire; the control group typically scores above 200, clinically stable IBD patients score an average of 169, and currently symptomatic IBD patients score below 150. Based on these studies, the following classifications for post-op quality of life were used in this study:

$\geq 200=$ Excellent

$151-199=$ Good

$101-150=$ Regular

$\leq 100=\mathrm{Bad}$

The scoring of the questions in all realms was transformed in the following way: The 1 to 7 scale was transformed into a 0 to 1 scale such that the values of the variables were altered from qualitative ordinal to quantitative, so as to facilitate statistical analysis and figure disposition.

The chi-square and Kruskal-Wallis tests were used to statistically assess the collected data.

The Pearson's chi-square test and Monte Carlo method were used to verify the existence of significant differences among the results of the IBDQ for different age groups and men and women.

For each area individually and for all of them combined, the Kruskal-Wallis test was used to verify if there were differences in the IBDQ scoring among the groups in relation to the proportions. A significance level of $\mathrm{p}<0.008$ due to the Bonferroni correction (multiple comparisons) was established for all statistical tests.

The study was evaluated and approved by the Ethics Committee of Hospital das Clinicas da Faculdade de Medicine da Universidade de São Paulo.

\section{RESULTS}

Between 1985 and 1995, 65 ulcerative colitis patients underwent proctocolectomy with ileal pouch-anal anastomosis at the Hospital das Clinicas da Faculdade de Medicina da Universidade de São Paulo. From this group, 12 patients still had an ileostomy for several reasons, 12 patients could not be reached because they lived in different states, and 5 patients had died for reasons other than the surgery.

A total of 36 patients were studied, 14 (38.9\%) males and $22(61.1 \%)$ females. The average and median ages were 45 and 44 years, respectively, while ages ranged from 28 to 64 years old
Using the classification defined in the Methodology section above for the IBDQ, the quality of life was considered excellent for 9, good for 11, regular for 13, and bad for 3 patients (Table 1).

Table 1 - Quality of life according to the IBDQ scoring

\begin{tabular}{llcc}
\hline SCORING - CLASSIFICATION & $\mathrm{n}$ & $\%$ \\
\hline$\geq 200$ & EXCELLENT & 9 & 25 \\
$151-199$ & GOOD & 11 & 30.6 \\
$101-150$ & REGULAR & 13 & 36.1 \\
$\leq 100$ & BAD & 3 & 8.3 \\
\hline
\end{tabular}

When comparing the IBDQ classification to gender, it was observed that the good results were observed predominantly for men; however, do not shows significant difference (Table 2).

Table 2 - Correlation between the IBDQ and gender

\begin{tabular}{lcc}
\hline IBDQ & \multicolumn{2}{c}{ GENDER - $\mathrm{n}(\%)$} \\
\cline { 2 - 3 } & Male & Female \\
\hline EXCELLENT & $4(28.6 \%)$ & $5(22.7 \%)$ \\
GOOD & $5(35.7 \%)$ & $6(27.3 \%)$ \\
REGULAR & $5(35.7 \%)$ & $8(36.4 \%)$ \\
BAD & $0(0 \%)$ & $3(13.6 \%)$ \\
\hline
\end{tabular}

Chi-square test of exact Monte Carlo, p-value $=0.597$

In the same way, when comparing the classification to age, it was observed that the bad results were most often associated with the older patients, but these differences were also not meaningful. Age was divided into two categories: Older than 55 (25\% of the patients) or younger than $55(75 \%$ of the patients), where in the results are shown in Table 3.

Table 3 - Correlation between the IBDQ and age

\begin{tabular}{lcc}
\hline IBDQ & \multicolumn{2}{c}{ AGE - n (\%) } \\
\cline { 2 - 3 } & \multicolumn{1}{c}{$\mathbf{5 5}$} & $\mathbf{2 5 5}$ \\
\hline EXCELLENT & $7(26.9 \%)$ & $2(20.0 \%)$ \\
GOOD & $9(34.6 \%)$ & $2(20.0 \%)$ \\
REGULAR & $9(34.6 \%)$ & $4(40.0 \%)$ \\
BAD & $1(3.8 \%)$ & $2(20.0 \%)$ \\
\hline
\end{tabular}

Chi-square test of exact Monte Carlo, valor-p $=0.447$

By applying the Kruskal-Wallis test using the Bonferroni correction in the comparison among the aforementioned areas, a significant difference $(\mathrm{p}$-value $<0.008)$ in the quality of life was detected when intestinal symptoms were compared to systemic symptoms (p-value $=0.006$ ) and when systemic symptomso were compared to the social aspects 
(p-value $=0.007)$, as shown in Table 1.

When the questions were analyzed within their own areas so as to identify the differences between the questions and separate those with the lowest scores from those with the highest, it was found that some of them were predominant and have a profound weight in the final scoring of the IBDQ. On the other hand, due to the small number of samples and great number of questions, it was not possible to make comparison inferences; only the descriptive analysis for the study of the questions within their own areas was possible.

In order to better understand the results and simplify the analysis, we named the questions by using keywords included in the questions themselves, as shown in Figures 2 through 5.

In the intestinal symptoms area, the lowest score was given for diarrhea (average $=0.58$, median $=0.57$, and standard deviation $=0.32$ ), while the highest was given for rectal bleeding (average $=0.91$, median $=1.0$, and standard

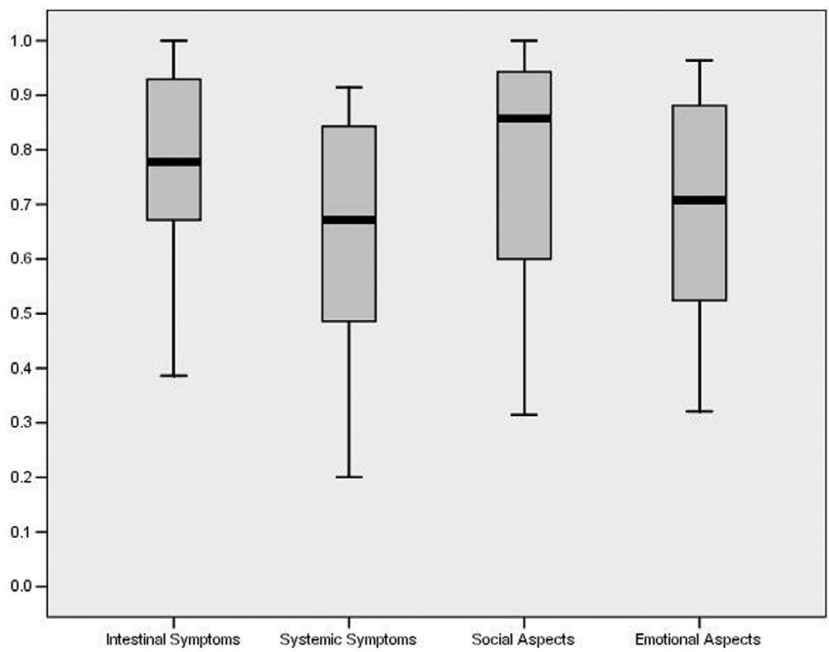

Figure 1 - Comparison among IBDQ areas Box-plot

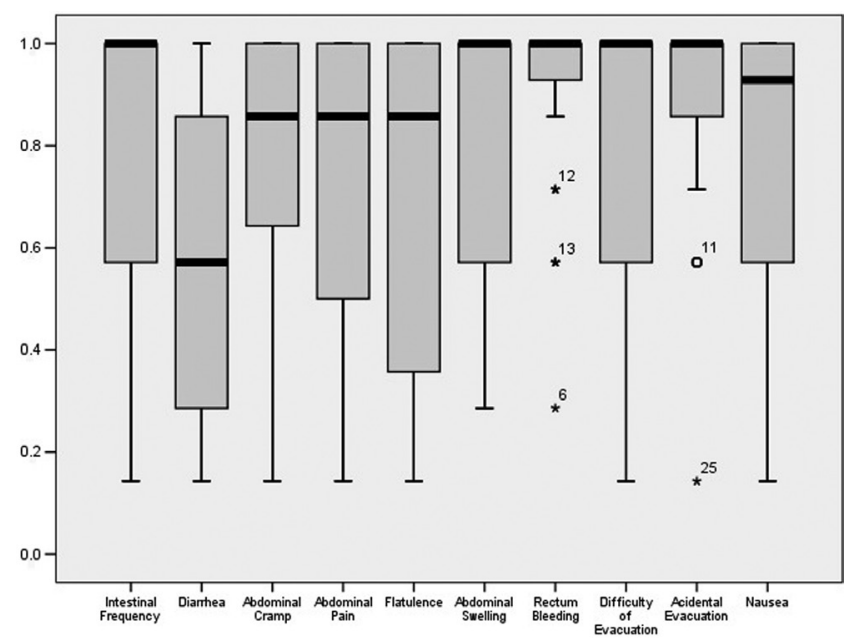

Figure 2 - Questions on the intestinal symptoms section Box-plot deviation $=0.17$ ), as presented in Figure 2.

By separately analyzing the questions in the systemic symptoms area to identify questions that had the greatest weight in their answers, it was noted that an adequate night of sleep, without having to wake up due to an intestinal problem, was the question that received the lowest score (average $=0.55$, median $=0.57$, and standard deviation $=$ 0.30). Moreover, this question received the lowest score on the entire IBDQ. In contrast, physical disposition received the highest score (average $=0.68$, median $=0.78$, and standard deviation $=0.25$ ), as depicted in Figure 3 .

In the social aspects area, the questions regarding places without restrooms (average $=0.63$, median $=0.71$, and standard deviation $=0.35$ ) and social appointments (average $=0.83$, median $=1.0$, and standard deviation $=$ 0.23 ) received the lowest and highest scores, respectively (Figure 4).

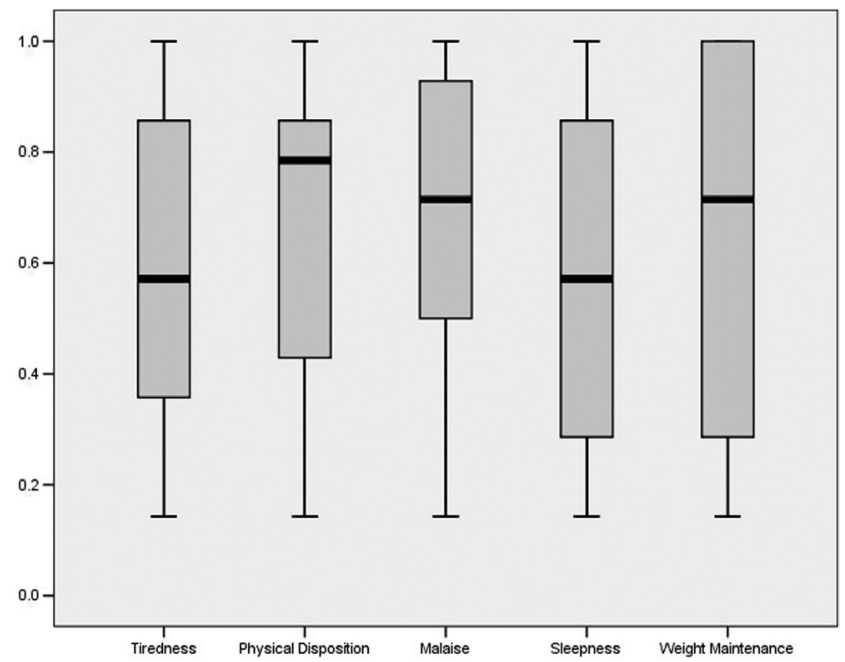

Figure 3 - Questions on the systemic symptoms section Box-plot

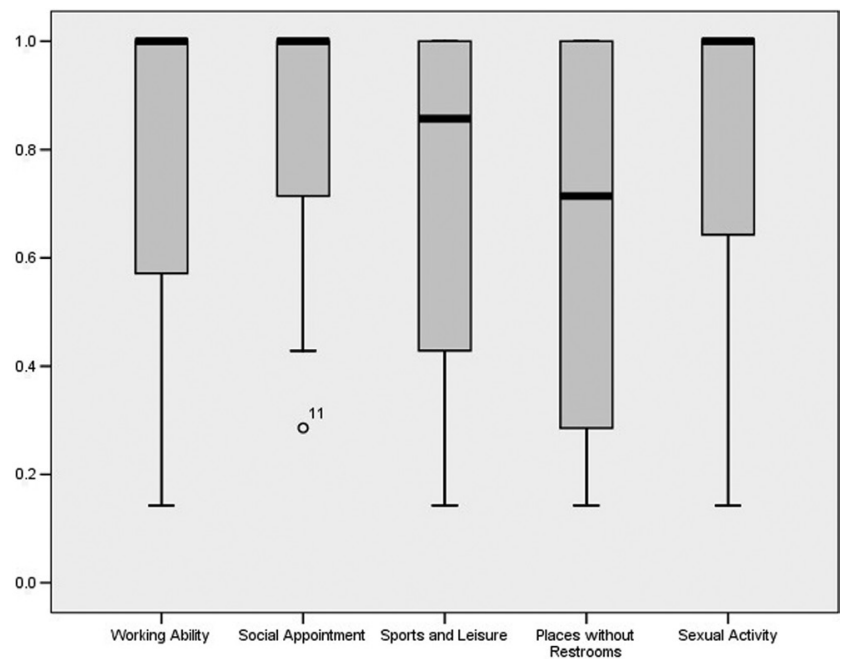

Figure 4 - Questions on the social aspects section Box-plot 
Finally, in the emotional aspects area, the questions regarding irritated (average $=0.57$, median $=0.57$, and standard deviation $=0.28$ ) and pleased and thankful for his/her personal life (average $=0.85$, median $=0.85$, and standard deviation $=0.20$ ) received the lowest and highest scores, respectively, as shown in Figure 5 . In addition, the question pleased and thankful for his/her personal life received the highest score in the questionnaire.

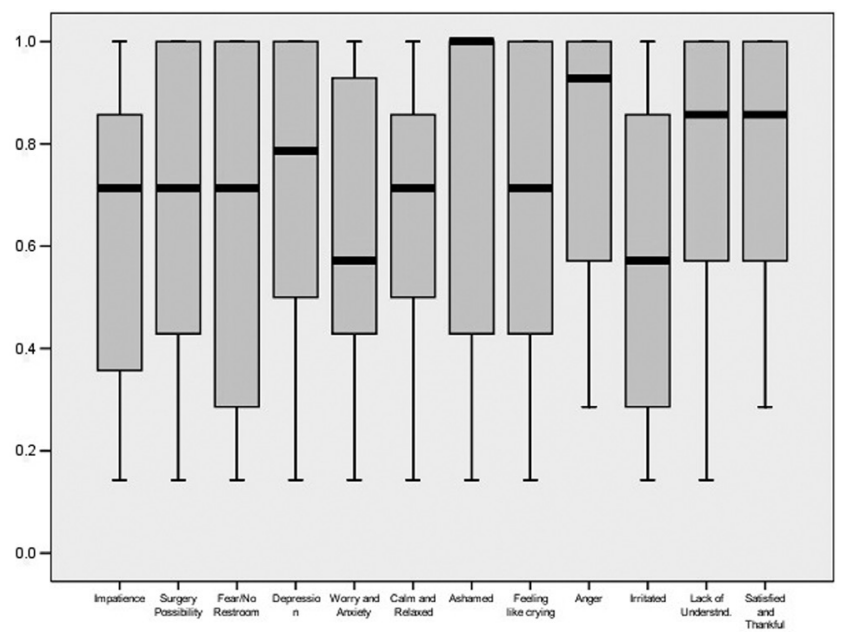

Figure 5 - Questions on the emotional aspects section Box-plot

\section{DISCUSSION}

The evaluation of quality of life should be done through quantitative and reproducible methods. The selection of the instrument should be based on the clarity of its components, definition of the target audience, and disease for which it was developed. In addition, this instrument should be easy to apply and easy to understand and have an appropriate time of use. ${ }^{21}$

The IBDQ was used in this study since it is a specific instrument with simple language, it has a viable time of use, and it is increasingly being accepted in literature. In addition, it has been translated and validated in the Portuguese language..$^{14}$

The quality of life for IBD patients after the creation of an ileal pouch was similar to that of the general population, which, according to LICHTENSTEIN et al., ${ }^{22}$ represents the re-establishment of a good quality of life in the postoperative stage for patients of all ages. FAZIO et al. ${ }^{12}$ observed the quality of life to be excellent or good for 93\% of the 645 patients studied after 40 months post-operation.

In our study, a similar result was obtained; however, a less positive result was obtained for the long post-operative period since the patients could have presented pouchitis and other complications. For some patients, surgery could not restore adequate intestinal function and in some cases caused sexual or fertility problems.

The difference in the quality of life between genders was not relevant. Furthermore, the question about sexual activity asked in the systemic symptom section did not present a low score. In fact, this question received nearly the highest score in that section.

The influence of age on the functionality of the ileal pouch was of constant concern in several studies comparing patients of different ages at the moment of surgery. JORGE et al. ${ }^{23}$ studied the recovery of anal sphincter functionality in 22 patients aged 50 years and older and could not identify any differences compared to 50 young patients. Nevertheless, the transitory damage of the inner anal sphincter was more severe in patients aged 50 years and older, even though there was total recovery after the closing of the ileostomy.

DELANEY et al., ${ }^{24}$ in a study composed of 1895 patients after a four-and-a-half-year follow-up, observed general satisfactory quality of life and functional results even in patients aged 65 years and older. This study, despite the seemingly bad results associated with patients aged 55 years and older, did not provide statistically significant results, showing that the long-term damage in quality of life is small. Therefore, $95 \%$ to $98 \%$ of the patients in this study would have undergone the surgery again, and the same percentage would recommend it to other patients.

By analyzing the questionnaire answers, 30 to $40 \%$ of the variations occasionally observed in the different sections can be explained by four independent variables: Pouchitis, ileal pouch post-operative complications, extraintestinal manifestations, and possible psychiatric disorders..$^{25}$ Regardless of the fact that complication risks are often associated with the ileal pouch, the most frequent being pouchitis, which can persist for long periods, the chance of removing the ileal pouch seems despicable after 10 years post-operation. $^{26}$

ALMEIDA et al. ${ }^{15}$ studied 30 patients who have undergone surgery at the Rectum and Colon Service at HCFMUSP after an average of five years post-operation, and they observed that $87 \%$ of these patients were satisfied with the surgery and that $73 \%$ reported an excellent or good quality of life.

We applied the IBDQ to the 30 patients previously interviewed by ALMEIDA et al. ${ }^{15}$ and to 6 other patients who had not been previously interviewed. In our study, we were able to determine an adequate and satisfactory quality of life, similar to that found in the literature. ${ }^{27,28}$ More specifically, $85 \%$ of the interviewed patients were satisfied and thankful for having undergone the surgery. McLEOD and BAXTER ${ }^{29}$ stated that the satisfaction achieved from having the surgery can be determined by the understanding 
that the treatment carried out was far better than any other alternative.

The quality of life considered excellent or good for $55.6 \%$ of the patients was lower than that formerly found in the ALMEIDA et al. ${ }^{15}$ study, which may be due to individually desired personal expectations, inadequate information about excessively optimistic expectations, and the extent of previously used drug dependency.

In this study, as well as in ALMEIDA et al., ${ }^{15}$ it could be verified that the intestinal and social areas were the areas that most influenced the results of the quality of life questionnaire. In addition, the systemic section presented the least weight in the final scoring of the IBDQ in both studies.

Biopsychosocial reasons were related to the quality of life. Even though patients reported mental and physical decay in comparison to the general population, after another assessment, they demonstrated a better result than was previously obtained. Medicine and psychotherapeutic methods for pain and managing anxiety can be taken into account when treating these patients so as to improve their quality of life. ${ }^{25}$

The psychological condition of the patient becomes clear when we observe that certain answers on the questionnaire influence the final scoring, for example, an adequate night of sleep and physical disposition for day-to-day activities, among others.

HAHNLOSER et al. ${ }^{30}$ studied the quality of life in patients who had been observed on a yearly basis. These patients have disclosed that proctocolectomy with ileal pouch-anal anastomosis presents good functional and quality of life results and remained stable even after 15 years postoperation. This same author later presented a case study of a 20-year observation period that showed adequate and satisfactory results. ${ }^{31}$ This study analyzed 1035 patients after a 10 -year period and 251 patients after a 20 -year period, wherein it was demonstrated that the number of continent patients, both during the day and at night, remained relatively stable. These results notwithstanding, a decrease in nocturnal continence has been noticed.
In our case study, it was noted that the lowest score on the IBDQ was for the question "an adequate night of sleep without having to get up due to an intestinal problem." It is worth mentioning that as the years go by, the sphincter strength declines and obstetrical trauma sequels may occur; that is, inflammatory bowel syndrome becomes more common with age.

These factors should be taken into account when loss of continence is observed after long periods of time.

The personal aspects involved in answering the questionnaire (the disclosure and fear) and the sub-answer trend of the patients, as well as the small number of patients presented in this case study, may influence the results obtained. Nonetheless, the results do not differ greatly from those presented in the literature.

There are few reports on the quality of life of ileal pouch post-operation patients in the national literature, and none of these reports cover a period of more than five years of observation. The high level of satisfaction obtained with this questionnaire shows that the ileal pouch procedure continues to be an adequate surgery with acceptable results, as demonstrated by the highest-scored question on the IBDQ.

The results found by surgeons, in which the patients are pleased to avoid a stoma, makes the procedure of sphincter preservation a focal point. The functional results should not be the only parameter that influences the choice of a procedure.

\section{CONCLUSION}

Most of the patients who have undergone proctocolectomy with sphincter preservation and ileal $\mathbf{J}$ pouch-anal anastomosis over ten years ago have presented a high score in the quality of life questionnaire (IBDQ). Therefore, it can be concluded that the possibility of sphincter preservation should always be considered, since patients remain clinically stable and have a good quality of life even after a long period post-operation.

\section{REFERENCES}

1. Teixeira MG, Habr-Gama A, Takiguti CK, Brunetti Neto C, Pinotti HW. Aspectos epidemiológicos da retocolite ulcerativa inespecífica no serviço de colo-proctologia do Hospital das Clínicas da Faculdade de Medicina da Universidade de São Paulo. Rev Bras Colo-Proct. 1991;11:87-91.

2. Tragnone A, Manau C, Bazzocchi G, Lanfranchi GA. Epidemiological characteristics of inflammatory bowel disease in Bologna, Italy incidence and risk factors. Digestion. 1993;54:183-8.

3. Lee EC, Truelove SC. Proctocolectomy for ulcerative colitis. World J Surg. 1980;4:195-201.
4. Parks AG, Nicholls RJ. Proctocolectomy without ileostomy for ulcerative colitis. Br Med J. 1978;2:85-8.

5. Brunetti Neto C, Habr-Gama A, Souza Jr AHS, Bocchini S, Pinotti HW. Anastomose ileoanal com reservatório ileal para tratamento da retocolite e da polipose familiar. In: $36^{\circ}$ Congresso Brasileiro de Colo-proctologia. Foz do Iguaçu, Brazil; 1987.

6. Kiss DR, Vilarino TC, Almeida MG. Tratamento cirúrgico da RCU e da polipose cólica familiar pela proctocolectomia com anastomose de reservatório ileal em J ao canal anal, com e sem mucosectomia retal. Rev Bras Colo-Proct. 1991;11:131-41. 
7. Habr-Gama A, Araújo SEA. Retocolectomia total e qualidade de vida. Arq Gastroenterol. 1996;37:45-7.

8. Williams NS, Johston D. The current status of mucosal protectomy and ileo-anal anastomosis in the surgical treatment of ulcerative colitis and adenomatous polyposis. Br J Surg. 1985;72:159-68.

9. Mchugh SM, Diamant NE, Mcleod R, Cohen Z. S-pouches vs. J-pouches: a comparison of functional outcomes. Dis Colon Rectum. 1987;30:671-7.

10. Sagar PM, Holdsworth PJ, Godwin PGR, Quirke P, Smith AN, Johnston D. Studies on manovolumetry, fecal bacteriology, fecal volatile fatty acids, mucosal morphology and functional results. Gastroenterology. $1992 ; 102: 520-8$

11. Salemans JMJI, Nagengast FM. Clinical and physiological aspects of ileal pouch-anal anastomosis. Scand J Gastroenterol. 1995;30:3-12.

12. Fazio VW, Ziv Y, Church JM, Oakley JR, Lavery IC, Jeffrey WM, et al. Ileal pouch anastomosis complications and function in 1005 patients. Ann Surg. 1995;222:120-7.

13. Orley J, Saxena S, Herrman H. Quality of life and mental illness. Reflections from the perspective of the WHOQOL. Br J Psychiatry. 2000;176:92-3

14. Pontes RMA, Miszputen SJ, Ferreira-Filho OF, Miranda C, Ferraz MB. Qualidade de vida em pacientes portadores de doença inflamatória intestinal: tradução para o português e validação do questionário "Inflammatory Bowel Disease Questionnaire" (IBDQ). Arq Gastroenterol. 2004:41:137-43.

15. Almeida MG, Kiss DR, Teixeira MG, Habr-Gama A. Qualidade de vida no seguimento tardio de doentes submetidos à proctocolectomia com bolsa ileal. Rev Bras Colo-Proct. 2000:20:145-53.

16. KISS, DR. Bolsite. Clínica Brasileira de Operação - Doença Inflamatória Intestinal, Livraria Atheneu Ed. 1997;3:149-56.

17. Martin F, Sutherland L, Beck IT. Oral 5-ASA versus prednisone in short-term treatment of Crohn's disease: a multicentre controlled trial. Can J Gastroenterol. 1990;4:452.

18. Greenberg GR, Feagan BG, Martin F, Sutherland LR, Thomson AB, Williams CN, et al. Oral budesonide in active Crohn's disease: results of a randomized placebo controlled, double-mind, multicenter trial. Canadian Inflammatory Bowel Disease Study Group. N Engl J Med. 1994;331:873-4

19. Irvine EJ, Feagan B, Rochon J, Archambault A, Fedorak RN, Groll A, et al. Quality of life: a valid and reliable measure of outcome for clinical trials in inflammatory bowel disease. Gastroenterology. 1994:106:28796.
20. Feagan B, Mcdonald JWD, Rochon J, Archambault A, Fedorak RN, Groll A, et al. Chronic low dose cyclosporine in the treatment of Crohn's disease. N Engl J Med. 1994;330:1846-51.

21. Yusuf SAI, Jorge JMN, Habr-Gama A, Kiss DR, Gama-Rodrigues J. Avaliação da qualidade de vida na incontinência anal: validação do questionário FIQL (Fecal Incontinence Quality of Life). Arq Gastroenterol. 2004;41:202-8.

22. Lichteinstein GR, Cohen R, Yamashita B, Diamond RH. Quality of life after proctocolectomy with ileoanal anastomosis for patients with ulcerative colitis. J Clin Gastroenterol. 2006;40:669-77.

23. Jorge JMN, Wexner SD, James K, Nogueras JJ, Jagelman DG. Recovery of anal sphincter function after the ileoanal reservoir procedure in patients over the age of fifty. Dis Colon Rectum. 1994;37:1002-5.

24. Delaney CP, Fazio VW, Remzi FH, Hammel J, Church JM, Hull TL, et al. Prospective, age-related analysis of surgical results, functional outcome, and quality of life after ileal pouch-anal anastomosis. Ann Surg. 2003;238:221-8.

25. Hauser W, Dietz N, Steder-Neukamm U, Janke K, Stallmach A Biopsychosocial determinants of health-related quality of life after ileal pouch anal anastomosis for ulcerative colitis. Inflamm Bowel Dis. 2004;10:399-407.

26. Farouk R, Pemberton JH, Wolff BG, Larson DR, Crownhart BS, Dozois RR. Functional Outcomes after Ileal Pouch-Anal Anastomosis for Chronic Ulcerative Colitis. Ann Surg. 2000;231:919-26.

27. Perrault J, Telander RL, Zinsmeister AR, Kaufman B. The Endorectal Pull-Throug Procedure in Children and Young Adults: A Follow-Up Study. J Pediatr Gastroenterol Nutr. 1998;7:89-94.

28. Skarsgard ED, Atkinson KG, Bell GA, Pezim ME, Seal AM, Sharp FR. Function and Quality of Life Results after Ileal Pouch Surgery for Chronic Ulcerative Colitis and Familial Polyposis. Am J Surg. $1989 ; 157: 467-71$

29. Mcleod RS, Baxter NN. Quality of Life of Patients with Inflammatory Bowel Disease after Surgery. World J Surg. 1998;22:375-81.

30. Hahnloser D, Pemberton JH, Wolff BG, Larson DR, Crownhart BS, Dozois RR. The Effect of Ageing on Function and Quality of Life in Ileal Pouch Patients. A Single Cohort Experience of 409 Patients with Chronic Ulcerative Colitis. Ann Surg. 2004;240:615-23.

31. Hahnloser D, Pemberton JH, Wolff BG, Larson DR, Crownhart BS, Dozois RR. Results at up to 20 years after ileal pouch-anal anastomosis for chronic ulcerative colitis. Br J Surg. 2007;94:333-40. 
